\title{
Specific Roles of NMDA and AMPA Receptors in Direction-Selective and Spatial Phase-Selective Responses in Visual Cortex
}

\author{
Casto Rivadulla, Jitendra Sharma, and Mriganka Sur \\ Department of Brain and Cognitive Sciences, Massachusetts Institute of Technology, Cambridge, Massachusetts 02139
}

Cells in the superficial layers of primary visual cortex (area 17) are distinguished by feedforward input from thalamic-recipient layers and by massive recurrent excitatory connections between neighboring cells. The connections use glutamate as transmitter, and the postsynaptic cells contain both NMDA and AMPA receptors. The possible role of these receptor types in generating emergent responses of neurons in the superficial cortical layers is unknown. Here, we show that NMDA and AMPA receptors are both involved in the generation of direction-selective responses in layer $2 / 3$ cells of area 17 in cats. NMDA receptors contribute prominently to responses in the preferred direction, and their contribution to responses in the nonpreferred direction is reduced significantly by GABAergic inhibition. AMPA receptors decrease spatial phase-selective simple cell responses and generate phase-invariant complex cell responses.

Key words: cat primary visual cortex; glutamate receptors; cortical networks; emergent responses; feedforward connections; recurrent connections
The circuitry of the cerebral cortex is marked by anatomical connections between neurons and by neurotransmitter receptor systems that impart specific functions to these connections. Cells in layer 4 of the adult primary visual cortex, for example, receive excitatory input from the lateral geniculate nucleus, from other cortical cells in layer 4, and from cells in layer 6 (Gilbert and Wiesel, 1979). These connections use glutamate as the neurotransmitter, acting primarily on AMPA receptors (Fox et al., 1989; see also Miller et al., 1989). In contrast, cells in the superficial layers of the cortex receive excitatory input primarily from layer 4 cells and from other layer $2 / 3$ cells. These connections also use glutamate, but the postsynaptic receptors include both AMPA and NMDA receptors (Fox et al., 1989, 1990). In addition, cells in all cortical layers receive inhibitory input, mediated primarily by GABA (Sillito, 1977; Tsumoto et al., 1979).

Although glutamate is an ubiquitous excitatory neurotransmitter in the cortex, the specific function of its receptor types in mediating unique cortical responses is unclear. NMDA receptors are commonly thought to play a role in the development of cortical circuitry, primarily as mediators of activity-dependent plasticity (Kirkwood and Bear, 1994; Katz and Shatz, 1996). AMPA receptors are commonly thought to play a role in normal, ongoing transmission between neurons. Yet, NMDA receptors in several regions of the adult brain, including the visual pathway, are known to be involved in the transmission of sensory information (Fox et al., 1989; Miller et al., 1989; Sillito et al., 1990; Kwon et al., 1991). Because the two receptor types have different characteristics [importantly, NMDA receptors are sensitive to the

Received Sept. 15, 2000; revised Dec. 18, 2000; accepted Dec. 18, 2000.

This work was supported by National Institutes of Health Grants EY07023 and NS39022 to M.S. and by a Fulbright-MEC Fellowship from Spain to C.R. We thank James Schummers for insightful discussions of this manuscript, Nigel Daw for comments, and Christine Waite for her help.

Correspondence should be addressed to Dr. Mriganka Sur, Department of Brain and Cognitive Sciences, Massachusetts Institute of Technology, E25-235, 45 Carleton Street, Cambridge, MA 02139. E-mail: msur@ai.mit.edu.

Dr. Rivadulla's present address: Neuroscience and Motor Control Group (NEUROcom), E U Fisioterapia, Campus de Oza, 15006 A Coruña, Spain.

Copyright (C) 2001 Society for Neuroscience $0270-6474 / 01 / 211710-10 \$ 15.00 / 0$ membrane potential (for review, see Dingledine, 1999) and to GABAergic inhibition (Artola and Singer, 1987; Shirokawa et al., 1989; Schroeder et al., 1997)], they may have different functional roles in cortical integration. A previous study (Fox et al., 1990) that examined the effect of NMDA receptor blockade in cat area 17 as a function of stimulus contrast found a proportionate reduction of responses at all contrasts. Conversely, application of NMDA caused a proportional increase in the response; application of quisqualate (a non-NMDA receptor agonist) increased responses by a constant amount independent of contrast.

We reasoned that selective blockade of AMPA or NMDA receptors while measuring responses would allow us to study the contribution of the other receptor to cortical cell properties. We have thus combined extracellular recording with iontophoresis of receptor antagonists in layer $2 / 3$ of cat area 17 to examine the role of NMDA and AMPA receptors in creating emergent responses that are particularly characteristic of these layers, namely, direction selectivity and complex cell responses (Hubel and Wiesel, 1962). Our data show that blocking NMDA receptors decreases the firing rate of cells but leaves direction selectivity and complex cell responses unaltered. Thus, AMPA receptors are sufficient for generating these responses. Blocking AMPA receptors in layer $2 / 3$ also decreases the firing rate but increases the direction selectivity of cells and the spatial phase selectivity of complex cells, making complex cell responses similar to those of simple cells. Thus, NMDA receptors are responsible for highly direction-selective responses. AMPA receptors decrease spatial phase-selective simple cell responses and are important for phase-invariant complex cell responses.

Parts of these data have been published previously in abstract form (Rivadulla et al., 1999).

\section{MATERIALS AND METHODS}

General preparation. All experiments were performed under protocols approved by Institutional Animal Care and Use Committee of the Massachusetts Institute of Technology and were in accord with National Institutes of Health guidelines. Adult female cats weighing between 1.5 and $2.5 \mathrm{~kg}$ were used. Animals were initially anesthetized with ketamine 

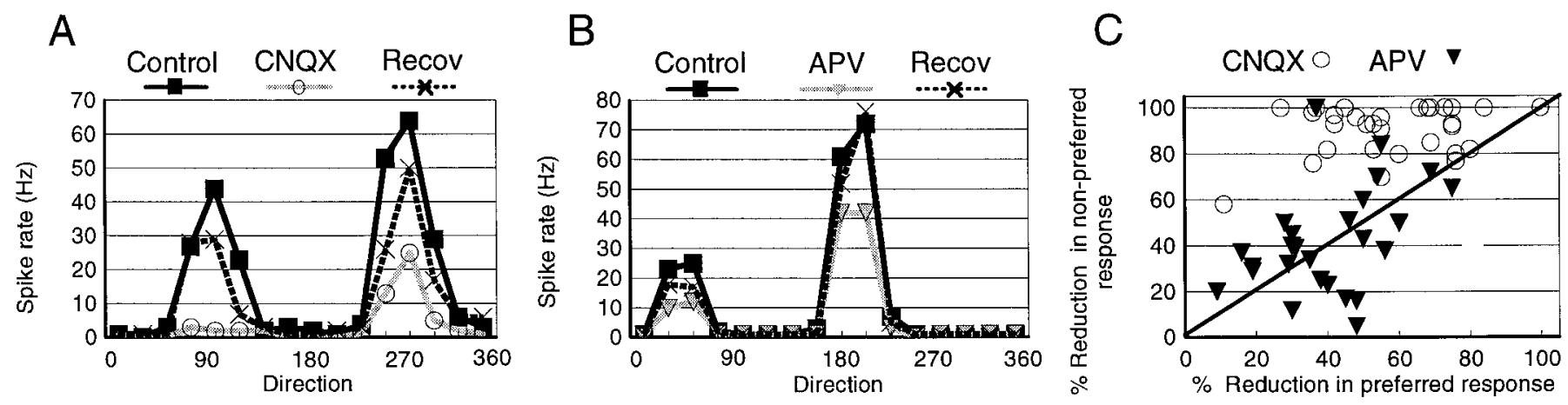

Figure 1. CNQX and APV have different effects on direction-selective visual responses of layer $2 / 3$ cells. $A$, Direction-tuning curves of a complex cell in the control condition, during CNQX iontophoresis, and after recovery. $B$, Direction-tuning curves from another complex cell in the control condition, during APV iontophoresis, and after recovery. $C$, Scatter plot for all of the cells in our study showing the effect of CNQX $(n=30)$ and APV $(n=27)$ in terms of proportion to the peak response of cells. Recov, Recovery.

$(15 \mathrm{mg} / \mathrm{kg})$ and xylazine $(1.5 \mathrm{mg} / \mathrm{kg})$. Atropine $(0.04 \mathrm{mg} / \mathrm{kg})$ was applied to reduce tracheal secretions. A tracheotomy was performed. During the experiment, the animal was anesthetized with isofluorane (typically $1 \%$ ) in nitrous oxide $(60 \%)$ and oxygen $(40 \%)$. The level of anesthesia was titrated carefully on the basis of the physiological state of the animal. The heart rate was continuously monitored and maintained at $\sim 180$ beats/ min. Expired $\mathrm{CO}_{2}$ was maintained at $4 \%$ by adjusting the respiratory rate and the inspired volume. Body temperature was automatically maintained at $37.5^{\circ} \mathrm{C}$ with a heating blanket and a rectal probe. A craniotomy and durotomy were performed at Horsley-Clark coordinates AP0 to 7 $\mathrm{mm}$ posterior and from the midline to $4 \mathrm{~mm}$ lateral. A stainless steel chamber was cemented to the skull with dental acrylic. Warm $1 \%$ agar was applied to the cortical surface. Muscular paralysis was induced with Norcuron (Organon; $0.1 \mathrm{mg} / \mathrm{kg}$ ), and the animal was artificially ventilated. Paralysis was maintained during the experiment with a continuous inf usion of Norcuron $\left(0.2 \mathrm{mg} \cdot \mathrm{kg}^{-1} \cdot \mathrm{hr}^{-1}\right.$, i.v. $)$. A mixture of $5 \%$ dextrose and lactated Ringer's solution was continuously inf used $(4 \mathrm{ml} / \mathrm{hr}$, i.v.) to maintain body fluids.

Pupils were dilated with atropine, and nictitating membranes were retracted with phenylephrine $\mathrm{HCl}$. The eyes were protected with contact lenses and focused at a distance of $57 \mathrm{~cm}$. The optic disks and retinal blood vessels were projected on a screen situated at the same distance to determine the position of the area centralis. Receptive fields were first hand-plotted using flashing and moving bars and classified as simple or complex (Hubel and Wiesel, 1962). Computer-controlled visual stimuli consisted of drifting square-wave gratings that were presented on a monitor with a mean luminance of $24 \mathrm{~cd} / \mathrm{m}^{2}$ at a contrast of 0.8 . The grating spatial and temporal frequency was set near-optimally for each cell. The typical spatial frequency was 0.5 cycle/degree, corresponding to at least one (and usually more) grating cycle within the receptive field. The typical temporal frequency was $1 \mathrm{~Hz}$. Stimuli were presented at eight orientations each at two opposite directions of motion (for a total of 16 directions). Each stimulus was presented for $2.5 \mathrm{sec}$; after it was flashed on, it remained stationary for the first $0.5 \mathrm{sec}$ and was then drifted for the next $2 \mathrm{sec}$. Stimuli were presented in random order and included two blank presentations to obtain spontaneous activity. Responses were collected for the entire duration of the stimulus and were averaged from seven presentations of each stimulus. Responses used for analysis were based on the total number of spikes obtained during stimulus motion (2 $\mathrm{sec})$. Spontaneous activity was subtracted from the total before calculation of the direction index.

Extracellular recording and iontophoresis. Multibarreled pipettes (three to five barrels) were used for extracellular recording and iontophoretic ejection of drugs. The barrels were filled with $\mathrm{NaCl}(3 \mathrm{M})$ for recording, D-2-amino-5-phosphonovaleric acid (APV; $50 \mathrm{~mm}$ ), pH 8, 6-cyano-7nitroquinoxaline-2,3-dione (CNQX; $1 \mathrm{~mm}), \mathrm{pH} 8$, bicuculline methiodide $(20 \mathrm{~mm}), \mathrm{pH} 4$, and fast green to mark the recording site. We used methods similar to those mentioned in the literature (Fox et al., 1990; Sillito et al., 1990) and used by us previously (Kwon et al., 1991) in analogous experimental conditions to establish a specific effect of CNQX on AMPA receptors and of APV on NMDA receptors at the applied doses. Briefly, ejection currents were in the range of 10-40 nA. After control data were collected, a drug was ejected until the visual response of the cell was diminished with respect to the control condition and reached a stable level of response. This usually happened after 2-3 min of continuous ejection of CNQX or APV. Stability was ascertained by comparing responses collected during the first and the last set of trials and establishing that there were not significant differences in the responses. Effective doses of CNQX to antagonize AMPA and not NMDA receptors were established by (1) ejecting a pulse of AMPA without, and then with, concurrent ejection of CNQX to demonstrate that CNQX antagonized the AMPA response and (2) ejecting a pulse of NMDA without and with concurrent ejection of CNQX to demonstrate that CNQX had no effect on the NMDA response. Similar trials were run to establish effective doses of APV, using NMDA and AMPA as agonists. In specific cells, we tested the dose of CNQX and APV by applying them together; the visual response was abolished in each instance. The dose of bicuculline was established by observing the effect on visual responses alone. Typical ejection currents were in the range of 15-25 nA. With these currents, after a few seconds we achieved an increase in the visual and spontaneous activity of cells that could be maintained for the duration of the visual stimulus without inducing burst discharges. When drugs were not ejected, a holding current of appropriate polarity was applied continuously. One of the barrels was filled with saline and used as a balance barrel. The pipette was moved with a mechanical microdrive, and its tip was placed at a depth between 300 and $800 \mu \mathrm{m}$ from the cortical surface. When a cell was isolated, we measured its response to the gratings and repeated the same protocol during ejection of APV, CNQX, or bicuculline and once more after a period of recovery. Only cells that showed recovery of responses to within $75 \%$ of control values were included in this study. After each penetration, we made a deposit of fast green that allowed us to confirm the recording site.

\section{RESULTS}

The results described here were obtained from 42 cells recorded in the supragranular layers of area 17 in adult cats.

\section{Effect of AMPA and NMDA receptors on visual responses}

Figure 1 illustrates the effects on visual responses of area 17 neurons when AMPA and NMDA receptors were blocked separately. We analyzed the effect of primarily NMDA-mediated responses (when AMPA receptors were blocked by iontophoresis of CNQX) and of primarily AMPA-mediated responses (when NMDA receptors were blocked with APV) by measuring proportional reductions in responses in the preferred and nonpreferred directions. Figure $1 A$ shows a cell in which AMPA receptor blockade by iontophoresis of CNQX reduced responses in the preferred direction by 59\% (39 spikes/sec) and responses in the nonpreferred direction by close to $100 \%$ (42 spikes/sec). In $94 \%$ (30/32) of the studied cells, AMPA receptor blockade produced a decrease in the firing rate. In $87 \%(26 / 30)$ of cells, the decrease was proportionally greater in the nonpreferred direction than in the preferred direction; in three cells, the decrease was similar 

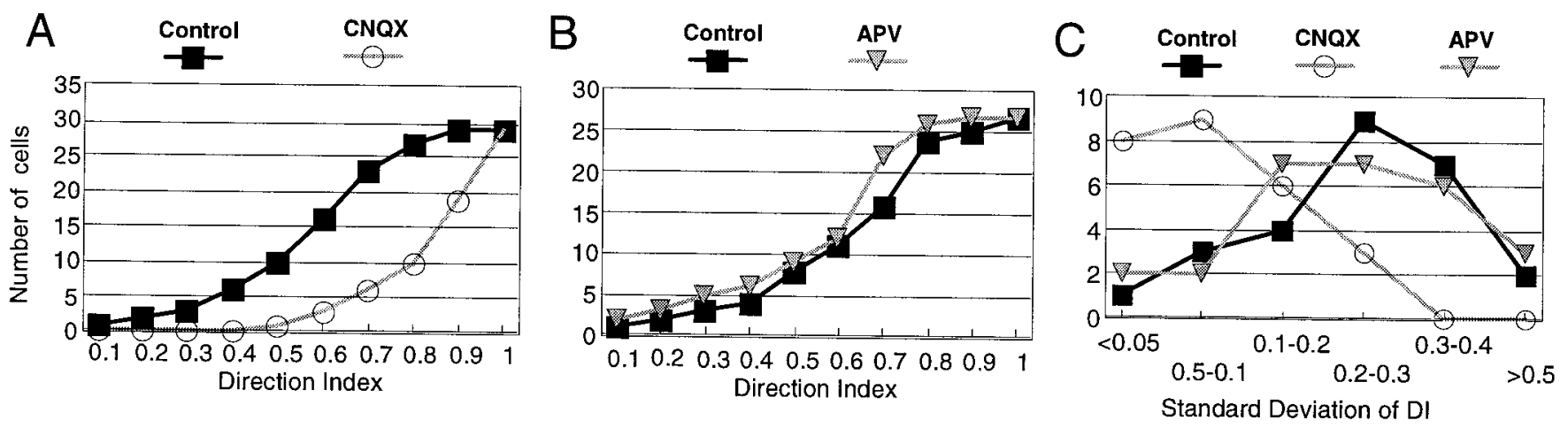

Figure 2. Effect of CNQX and APV on the direction index of layer $2 / 3$ cells. $A$, Cumulative histogram showing the effect of CNQX $(n=30)$. $B$, Cumulative histogram showing the effect of APV $(n=27)$. $C$, Histogram showing the effect of APV and CNQX on the variability of the DI. The $x$-axis represents the SD of the DI calculated trial by trial, which we used as a measure of the variability. The $y$-axis represents the number of cells in each bin.

$(80 \%)$ in both directions, whereas in one cell, all responses were abolished by CNQX.

Blockade of NMDA receptors also reduced the firing rate in $77 \%(27 / 35)$ of area 17 cells, affecting both preferred and nonpreferred responses. For example, in the cell shown in Figure $1 B$, iontophoresis of APV reduced the preferred response by $46 \%$ (30 spikes/sec) and the nonpreferred response by $51 \%$ (12 spikes/sec). The percentage reduction obtained with APV was comparable in the nonpreferred and preferred directions, indicating that AMPA receptors contribute to responses in both directions.

Figure $1 C$ shows a scatter plot of the effects of CNQX and APV on preferred and nonpreferred responses in each of the cells in our sample, expressed as a percentage reduction of the peak response. CNQX and APV had similar effects on preferred responses, but the reduction in nonpreferred responses was significantly greater under CNQX than under APV ( $p<0.01, t$ test). APV had equivalent effects on the two components in proportional terms (Fig. 1C) $(p>0.05)$, whereas CNQX reduced nonpreferred responses significantly more than preferred responses (Fig. 1C) $(p<0.01)$. Thus CNQX and APV affected preferred and nonpreferred response components differently.

\section{Effects on direction selectivity}

Blockade of AMPA receptors had dramatic effects on the direction selectivity of area 17 cells. Because of the drastic reduction in nonpreferred responses, responses that remained in the presence of CNQX were primarily in the preferred direction. The direction index $[\mathrm{DI}=$ (maximum response - opposite response)/ maximum response] under CNQX for our cell population $(n=29$ cells) was significantly greater than that in the control condition (Fig. 2A) ( $p<0.01$, Kolmogorov-Smirnov test). Indeed, nearly half the cells had an index $>0.9$, indicating preferred responses that were $>10$ times larger than nonpreferred responses. In contrast, the DI under APV for our population was not different from that of control (Fig. $2 B)(p>0.05$, Kolmogorov-Smirnov test), consistent with the data of Figure 1, in which APV caused a proportional reduction in preferred and nonpreferred responses. These results demonstrate that responses that remain after AMPA receptor blockade are highly skewed toward the preferred direction whereas responses that continue after NMDA receptor blockade are proportional to control responses in both preferred and nonpreferred directions.

Blockade of AMPA receptors not only leads to an increase in the DI but also to a decrease in the variability of the index. The $\mathrm{SD}$ of the DI was calculated as a measure of the variability between trials. Figure $2 C$ shows the SD of the population in the control condition and during CNQX and APV ejection. The values were significantly lower under CNQX than during control conditions ( $p<0.01, t$ test). APV did not produce any change when compared with the control values $(p>0.05)$. Thus, direction-selective responses mediated by NMDA receptors alone are much more reliable than are responses mediated by AMPA receptors alone or control responses mediated by a combination of NMDA and AMPA receptors.

Blocking inhibition increases preferred and nonpreferred responses, allowing a direct examination of whether inhibition interacts with glutamate receptors to affect specific response components. Thus, we examined the effect of blocking inhibition concurrent with blockade of AMPA responses (Fig. 3) or NMDA responses (Fig. 4) in preferred and nonpreferred directions. Figure $3 A$ shows direction-tuning curves from a cell under different conditions. In the control condition, this cell preferred a direction of 225 degrees and had a DI $=0.67$. During iontophoresis of CNQX, the preferred response was reduced substantially (by 22 spikes/sec or $60 \%$ ), whereas the nonpreferred response was reduced to zero (by 10 spikes/sec), causing a DI $=1.0$. Bicuculline made the orientation tuning broader; the firing rate of the cell increased by $76 \%$ in the preferred direction and by $235 \%$ in the nonpreferred direction, decreasing the DI to 0.36. Simultaneous ejection of CNQX now reduced preferred and nonpreferred responses approximately proportionately (corresponding to reductions of 34 and 25 spikes/sec, respectively) with respect to the bicuculline condition and led to a DI $=0.5$. Thus, there is a substantial non-AMPA (i.e., NMDA)-mediated component present in the nonpreferred direction during bicuculline ejection, which persists during application of CNQX plus bicuculline and reduces the DI relative to $\mathrm{CNQX}$ alone.

Figure $3 B$ shows in more detail the effect of combining bicuculline with CNQX, in a different cell. The black line represents the peristimulus time histogram (PSTH) in the preferred direction, and the gray line represents the PSTH in the nonpreferred direction. Bicuculline increased both preferred and nonpreferred responses (see Fig. $3 B$, right, the compressed scale on the $y$-axes). During CNQX ejection the cell became highly directional because of a near-complete reduction of nonpreferred responses. However, with CNQX and bicuculline applied concurrently, there was a proportionately similar decrease in preferred responses (peak reduction, 37 spikes/sec) and nonpreferred responses (41 spikes/sec) compared with the bicuculline condition. 
A

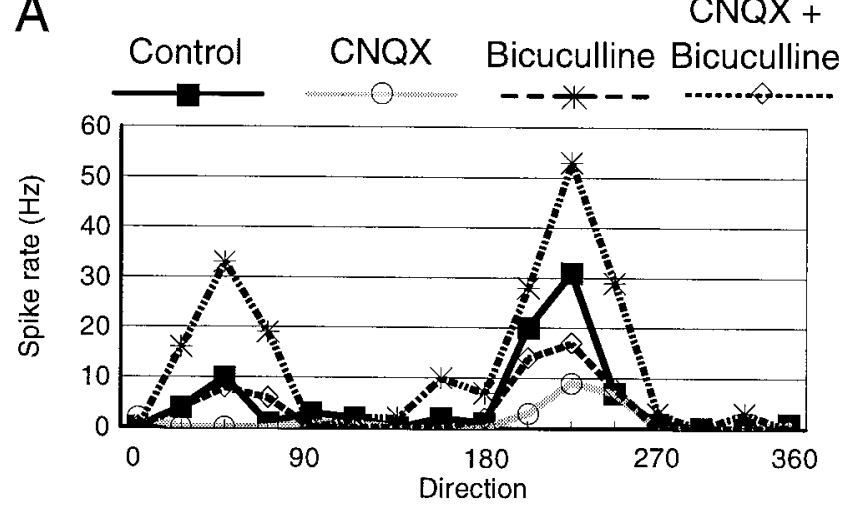

$B$
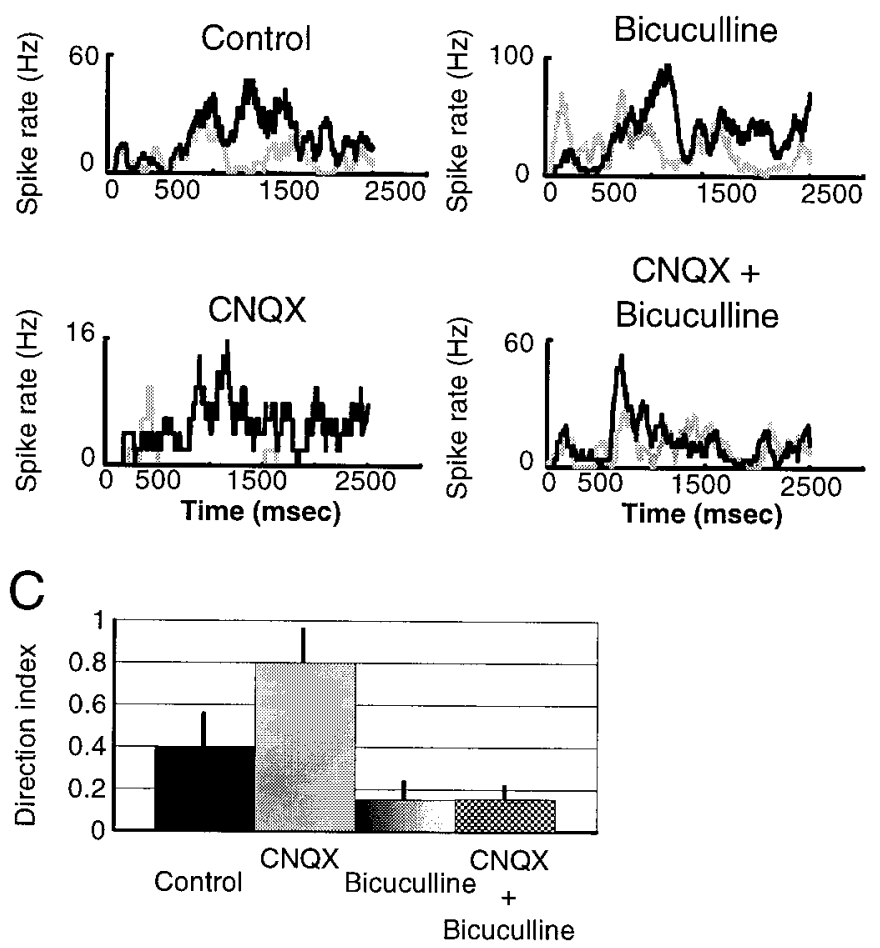

Figure 3. Interactions between AMPA and GABA receptors during direction-selective responses. $A$, Direction-tuning curves of a complex cell in the control condition and during ejection of CNQX, bicuculline, and both simultaneously. $B$, Peristimulus time histograms of responses from another complex cell showing the control response and the effect of the drugs on the preferred (shown in black) and nonpreferred (gray) directions. Each histogram is the average response to seven stimulus presentations and shows the entire $2.5 \mathrm{sec}$ of stimulus duration; the grating was stationary for the first $500 \mathrm{msec}$ and drifted for the next $2 \mathrm{sec}$. $C$, Bar histogram showing the mean value $( \pm \mathrm{SD})$ of the direction index for the population of cells in the different conditions $(n=4)$.

The effect of concurrent application of CNQX and bicuculline on preferred and nonpreferred responses was spread throughout the stimulus time period. These results were similar in all tested cells.

The average DI in the different conditions involving blockade of inhibition and AMPA receptors in all of the cells studied $(n=4)$ is shown in Figure 3C. Application of CNQX alone increased the DI of cells relative to that of control $(p<0.05, t$ test). Bicuculline alone decreased the DI relative to that of control $(p<0.05)$, principally by a disproportionate increase in nonpreferred responses (Fig. 3A). Concurrent application of CNQX and bicuculline removed proportional response compo-
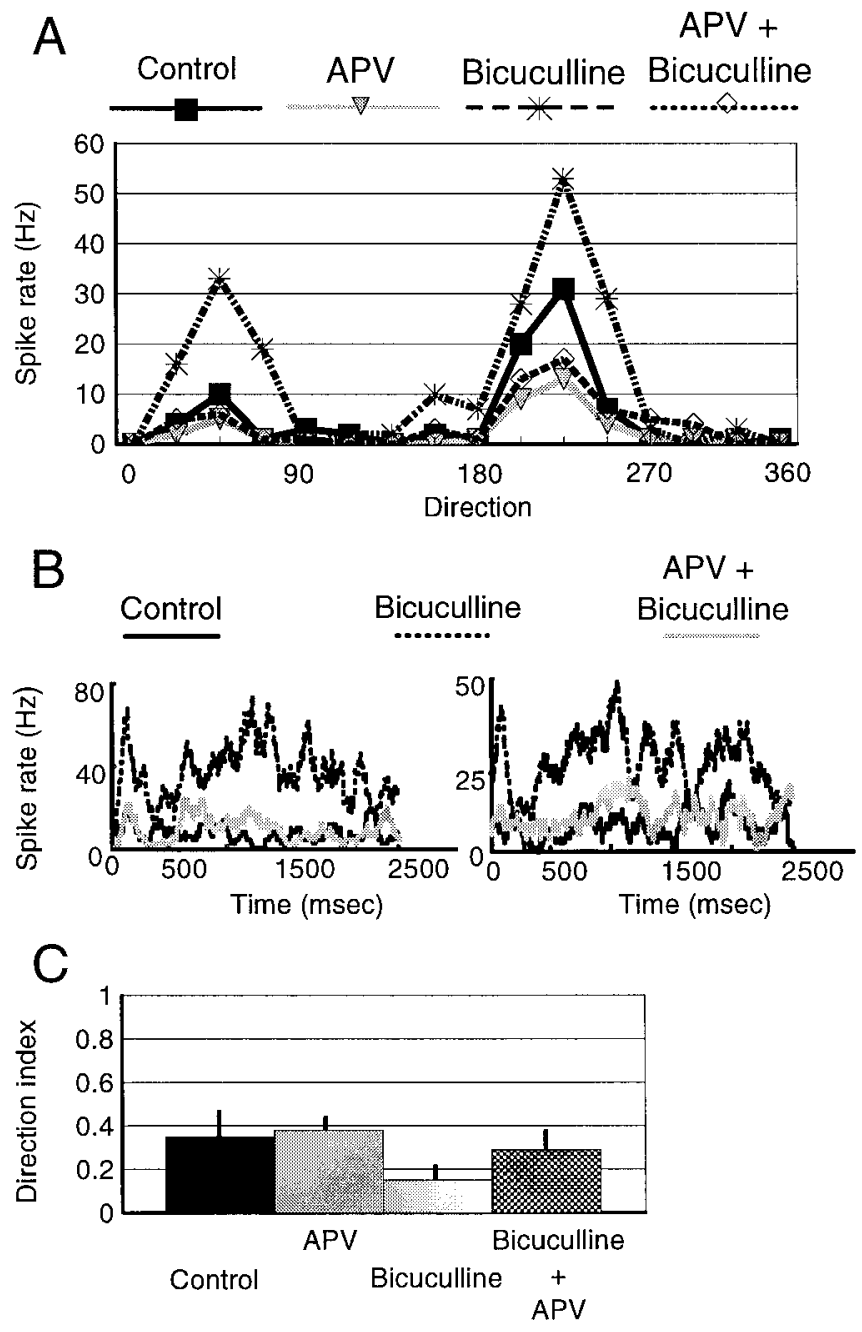

Figure 4. Modulation of NMDA activity by GABA during generation of direction-selective responses. $A$, Direction-tuning curves from the same cell shown in Figure $3 A$ in the control condition and during ejection of APV, bicuculline, and both simultaneously. $B$, Peristimulus time histogram of nonpreferred responses of two simple cells showing the effect of bicuculline and APV plus bicuculline. See the legend to Figure 3 for details. Blockade of inhibition by bicuculline preferentially increases the nonpreferred response, because of primarily an NMDA-mediated component; simultaneous application of APV reduces the response to the control level. Thus, GABAergic inhibition preferentially affects the NMDA response component in the nonpreferred direction. $C$, Bar histogram showing the mean $( \pm \mathrm{SD})$ of the direction index for the population of cells in the different conditions $(n=4)$.

nents from preferred and nonpreferred directions, leaving the DI unchanged $(p>0.05)$. This is in contrast to CNQX application with inhibition intact, which causes a disproportionate reduction in nonpreferred responses and an increase in the DI (compare Figs. $1 C, 2 A)$.

The nonpreferred response that remains after concurrent ejection of CNQX and bicuculline is mediated by NMDA receptors, indicating that GABAergic inhibition significantly regulates the NMDA response component in the nonpreferred direction. To test this hypothesis, we compared the response under bicuculline at the same time that we blocked the NMDA response. Figure $4 \mathrm{~A}$ shows direction-tuning curves from the same cell shown in Figure $3 A$. During APV iontophoresis, the nonpreferred response of the cell was reduced by $50 \%$ (from 10 to 5 spikes/sec), and the 
preferred response was reduced by $58 \%$ (from 31 to 13 spikes/ $\mathrm{sec})$. Bicuculline increased the nonpreferred response proportionately more than the preferred, but the effect of bicuculline was countered rather precisely by concurrent ejection of APV; i.e., APV now reduced nonpreferred responses to a disproportionately greater extent. This effect of APV, in the presence of bicuculline, on nonpreferred responses was observed in all cells tested $(n=4)$. Figure $4 B$ shows PSTHs from two different cells responding in the nonpreferred direction, each in the control condition, during bicuculline ejection and during simultaneous ejection of bicuculline and APV. Bicuculline clearly increased the firing rate of each cell, and the effect was reversed by APV throughout the stimulus duration. Figure $4 C$ shows the DI in the different conditions averaged for the four cells. Importantly, bicuculline reduced the DI compared with the control or APV condition ( $p<0.05, t$ test), but the DI was almost completely restored by the concurrent application of APV $(p<0.05)$. The percentage reduction in responses obtained during application of APV plus bicuculline, compared with bicuculline alone, was greater in the nonpreferred than the preferred direction $(p=$ 0.05). This contrasts with the effect of APV with intact inhibition (Fig. 1C), which causes proportionately the same reduction in nonpreferred and preferred responses. Thus, GABAergic inhibition acts to reduce NMDA-mediated responses preferentially in the nonpreferred direction.

\section{Effects on phase selectivity of simple and complex cells}

If AMPA receptors contribute to both preferred and nonpreferred responses whereas NMDA receptors contribute disproportionately to preferred responses, the two receptors may have specific roles in other kinds of integration that occur in the superficial layers of area 17 . Thus, we examined the time course and relative phase of responses in simple and complex cells during blockade of AMPA and NMDA receptors. We classified cells as simple or complex on the basis of the structure of the receptive field (Hubel and Wiesel, 1962). CNQX and APV affected the DI of simple cells $(n=13)$ and complex cells $(n=17)$ to a similar extent $(p>0.05, t$ test). However, AMPA receptor blockade changed the response phase and modulation of complex cells. Figure $5 A$, left, shows PSTHs of a complex cell responding in the preferred stimulus direction in the control condition, during CNQX ejection, and after recovery. The control PSTH shows the typical absence of clear modulation in a complex cell response when stimulated with a drifting grating. CNQX reduced the firing rate but also changed the temporal pattern of response. There was now a clear modulation of the response, similar to that expected from a simple cell rather than a complex cell. Iontophoresis of APV also reduced responses in the preferred direction but did not change the temporal pattern of response (Fig. $5 A$, right). In simple cells, neither CNQX nor APV caused a substantial change in the temporal response pattern (Fig. $5 B$ ).

We calculated the mean (F0) and first (F1) Fourier components of response to drifting gratings from the PSTHs in the control condition and during ejection of CNQX or APV. The F1/F0 ratio provides a measure of the modulation of response in a cell; a high ratio $(>1)$ characterizes simple cells, whereas a low ratio $(<1)$ is characteristic of complex cells (Movshon et al., 1978a,b; Skottun et al., 1991). The histogram in Figure $6 A$ shows the F1/F0 values obtained for our population in control conditions. The histogram clearly shows a bimodal distribution of cells indicative of the

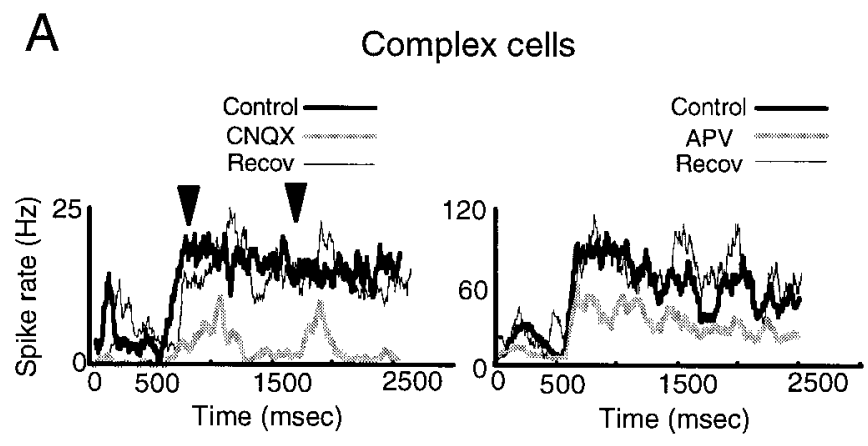

B Simple cells

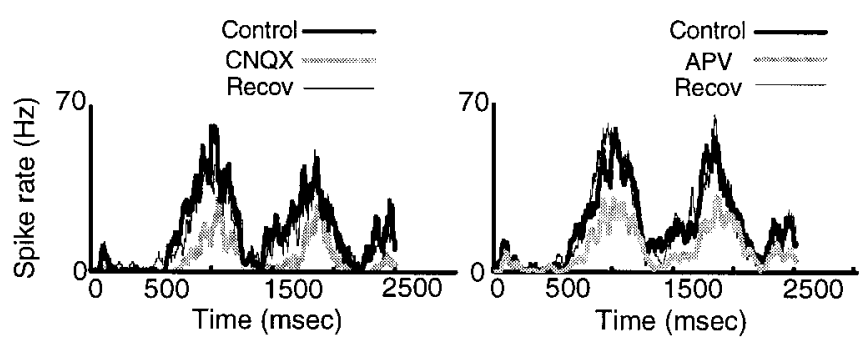

Figure 5. AMPA receptors underlie the spatial phase-insensitive responses of complex cells. $A$, Peristimulus time histograms showing the response of two complex cells to a drifting grating moving in the preferred direction during the control condition and ejection of CNQX (left) and APV (right) and after recovery. See the legend to Figure 3 for details. During CNQX ejection, the response of the cell is modulated substantially by the grating; arrowheads show the response of the cell at the grating temporal frequency $(1 \mathrm{~Hz})$. During APV ejection, there is a reduction in the response but no pronounced phase-selective modulation. $B$, The effect of CNQX (left) and APV (right) on the response of a simple cell, showing little change in the temporal modulation of the response.

existence of two subpopulations, with complex cells at ratios $<1$ and simple cells at ratios $>1$.

The scatter plots in Figure $6 B$ show the effect of CNQX and APV on the F1/F0 ratio for each cell in our population. CNQX caused a significant increase in the F1/F0 ratio in complex cells compared with control $(n=16)$ but had little effect on simple cells $(n=13)$. APV had little effect on the F1/F0 ratio in either complex or simple cells relative to control $(n=16$ complex cells, 13 simple cells). The average change in F1/F0 for the different conditions is shown in Figure $6 C$. Only CNQX application to complex cells significantly changes the $\mathrm{F} 1 / \mathrm{F} 0$ ratio $(p<0.01$, Kolmogorov-Smirnov test). Thus, AMPA receptors appear to mediate the spatial phase independence of complex cell responses in the superficial layers of area 17 by nonspecifically decreasing phase-selective modulation.

Inhibition has been proposed to contribute to the generation of simple and complex cell properties; specifically, blockade of inhibition widens On and Off subfields of simple cells, and the increased overlap between subfields might make their responses similar to those of complex cells (Sillito, 1975; Pernberg et al., 1998) (see also Discussion). We therefore blocked inhibition with bicuculline to examine whether the F1/F0 ratio was reduced, particularly in simple cells to make responses more complex-like, and combined it with the ejection of CNQX to examine whether the ratio was subsequently increased, reverting responses to those resembling simple cells. Figure $7 A$ shows PSTHs from a simple cell responding to a drifting grating moving in the preferred 
A

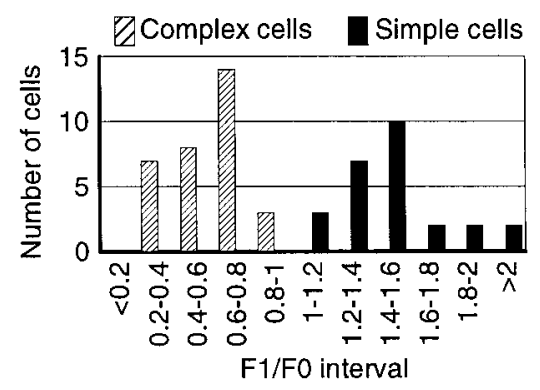

C

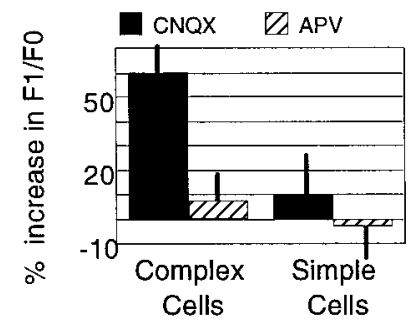

B

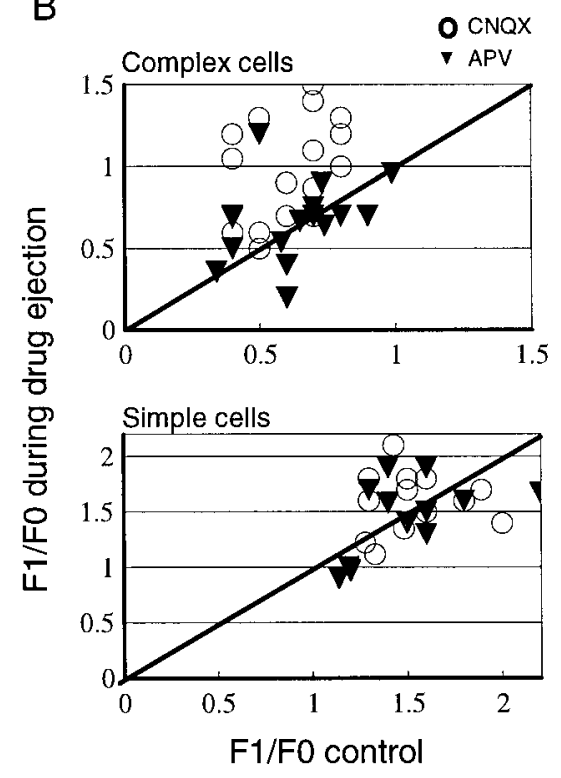

Figure 6. Effect of CNQX and APV on responses of simple and complex cells. $A$, Histogram of $\mathrm{F} 1 / \mathrm{F} 0$ values of simple and complex cells in the control condition. F1 is the amplitude of the first Fourier component of response, showing modulation at the grating temporal frequency. F0 is the DC or mean response level. $B$, Scatter plot showing the change in F1/F0 for each complex cell (top; $n=16$ ) and simple cell (bottom; $n=13$ ) during CNQX and APV ejection. $C$, Histogram showing the variation in the F1/F0 ratio under CNQX and APV for simple and complex cells. The F1/F0 ratio increases significantly for complex cells under CNQX, denoting an increase in the temporal modulation of responses by the grating.
A

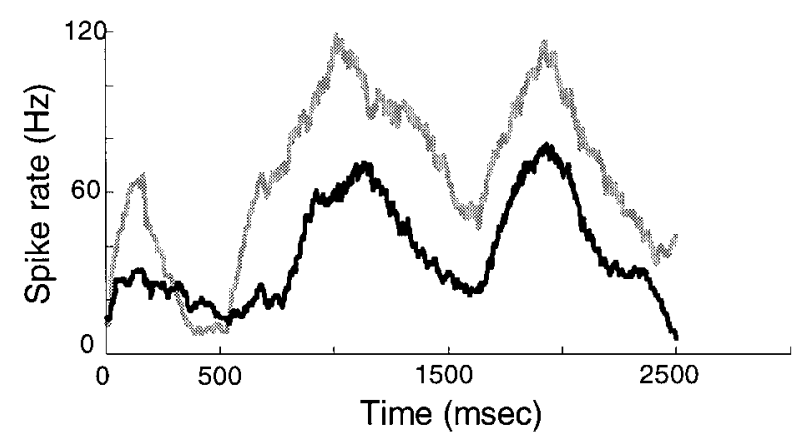

B
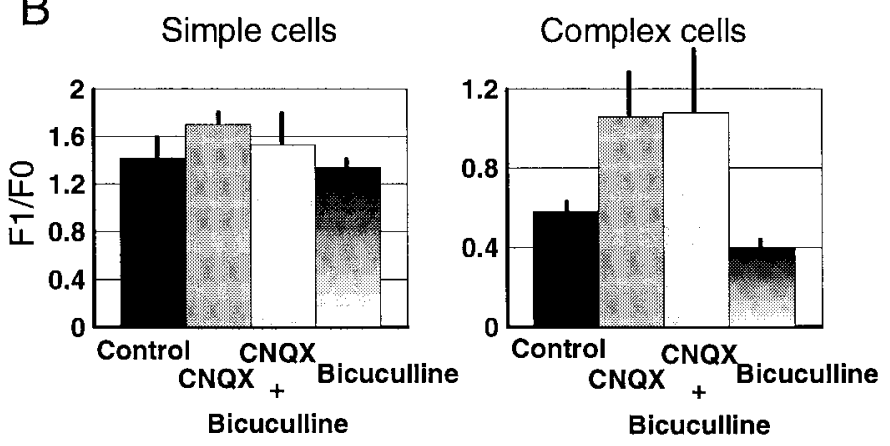

Figure 7. Blockade of inhibition does not affect the temporal modulation of simple or complex cell responses. $A$, Peristimulus histogram of the response of a simple cell to a grating drifting in the preferred direction, in the control condition and during bicuculline application. See the legend to Figure 3 for details. $B$, The effect of bicuculline, CNQX, and bicuculline plus $\mathrm{CNQX}$ on $\mathrm{F} 1 / \mathrm{F} 0$ values of simple cells (left; $n=3)$ and complex cells $($ right $n=3)$. Vertical bars show the mean $( \pm \mathrm{SD})$.

direction, in the control condition and during bicuculline application. Bicuculline increased the firing rate but did not substantially modify the modulation of the response $(\mathrm{F} 1 / \mathrm{F} 0=1.59$ in the control condition and 1.34 during bicuculline application). Figure $7 B$ shows that there was no effect on the $\mathrm{F} 1 / \mathrm{F} 0$ ratio of bicuculline application or of CNQX applied separately or together with bicuculline on simple cells ( $p>0.05, t$ test, for all comparisons; $n=3$ ). In complex cells, there was a possible decrease in the $\mathrm{F} 1 / \mathrm{F} 0$ ratio during bicuculline application $(p=0.2)$. However, in agreement with data shown previously (Figs. 5, 6), application of CNQX caused an increase in the ratio when applied alone or together with bicuculline ( $p=0.05$ for each comparison; $n=3$ ). APV had no effect on the F1/F0 ratio of either simple cells or complex cells when applied alone or together with bicuculline $(p>0.05 ; n=3)$. Thus, blockade of inhibition does not affect temporal response modulation in simple or complex cells, and the effect of blocking AMPA receptors is to increase phase-selective modulation even when inhibition is removed.

\section{DISCUSSION}

We have used direction selectivity and modulation of phase selectivity in simple and complex cell responses as probes for the function of AMPA and NMDA receptors in the supragranular layers of area 17. By combining extracellular recording and iontophoresis of receptor blockers, we demonstrate the following results: (1) Blocking AMPA receptors removes a proportionately larger component from nonpreferred compared with preferred responses and increases direction selectivity. The remaining responses are mediated by NMDA receptors and are overwhelmingly in the preferred direction. (2) Blocking NMDA receptors removes proportional components from preferred and nonpreferred responses and preserves directional selectivity. Because the remaining responses are mediated by AMPA receptors, these receptors are sufficient for direction selectivity. (3) Blocking inhibition preferentially enhances the contribution of NMDA receptors to nonpreferred responses and reduces direction selectivity. Thus, inhibition contributes to direction selectivity by reducing NMDA responses in the nonpreferred direction. (4) Blocking AMPA receptors increases the modulation of complex cell responses by a drifting grating stimulus. Thus, AMPA receptors decrease the selectivity of complex cells for spatial phase or the spatial location of visual stimuli. (5) Blocking NMDA receptors or inhibition has little effect on the temporal modulation of simple or complex cell responses. Together, these results allow us to propose specific roles for NMDA and AMPA receptors in 
direction selectivity in the superficial layers of area 17 and in the generation of phase selectivity by simple and complex cells in these layers.

\section{Direction selectivity in supragranular layers of cortex}

Direction selectivity first appears in simple cells of layer 4 in area 17 (Hubel and Wiesel, 1962), where NMDA receptors are not present in significant proportions (Rosier et al., 1993; Gordon et al., 1995; Gutierrez-Igarza et al., 1996) and contribute little to visual responses (Fox et al., 1989, 1990; but see Miller et al., 1989). The mechanism(s) by which direction selectivity is generated and whether the mechanism is similar in various cortical layers remain unresolved. One hypothesis is that inhibition reduces the response in the nonpreferred direction (Barlow and Levick, 1965; Goodwin and Henry, 1975; Bishop et al., 1980; Ganz and Felder, 1984). The hypothesis is supported by pharmacological studies in cat (Sillito, 1975, 1977; Tsumoto et al., 1979; Nelson et al., 1994; Crook et al., 1997, 1998) and monkey (Sato et al., 1995), demonstrating that blockade of inhibition in cortical cells induces a loss of selectivity to the direction of stimulus motion. An alternative hypothesis is that there is enhancement of excitation in the preferred direction. It has been shown (Reid et al., 1987, 1991; McLean and Palmer, 1989; Jagadeesh et al., 1993, 1997; Livingstone, 1998; Murthy et al., 1998) that simple cells in area 17 have asymmetries in the time course of the response evoked from different positions of the receptive field. Linear summation of these asymmetries allows one to predict the direction preference of the cell but also leads to an overestimation of the response in the nonpreferred direction. Recurrent excitation has been proposed as a nonlinear mechanism by which responses can be increased in the preferred direction (Douglas et al., 1995; Suarez et al., 1995). Recently, it has been postulated (Livingstone, 1998) that inhibition can sculpt the spatiotemporal profile of the receptive field, accentuating spatiotemporal asymmetry and increasing direction selectivity, particularly in layer 4 (Murthy and Humphrey, 1999; see also Taylor et al., 2000).

A fundamental difference between layers $2 / 3$ and 4 is the presence in supragranular layers of NMDA receptors, where they have been shown to participate in transmission in vivo (Fox et al., 1989, 1990) and in vitro (Shirokawa et al., 1989). Our data indicate that AMPA and NMDA receptors both contribute to direction selectivity in supragranular layers (Fig. $8 A$ ). AMPA receptors are sufficient for generating direction selectivity (Fig. $8 C$ ), either because inputs to the superficial layers conveyed by AMPA receptors are already biased for direction or because feedforward and recurrent connections mediated by AMPA receptors generate direction selectivity within these layers (Douglas et al., 1995). NMDA receptors by themselves can generate highly directionselective responses (Fig. $8 B$ ), by summing and/or amplifying responses to the preferred stimulus while contributing less to nonpreferred responses because of close GABAergic control. One possibility is that NMDA receptor activation is possible only with enough excitation in the preferred direction. However, a comparison of the nonpreferred and spontaneous responses that remain after CNQX application (spontaneous activity in our population of cells is reduced on average by only $28 \%$ under CNQX, whereas nonpreferred responses are reduced by $88 \%$ ) suggests that the reduced contribution of NMDA receptors to nonpreferred responses is likely mediated by active inhibition rather than simply being a function of overall response magnitude: spontaneous activity occurs under less inhibition than non-

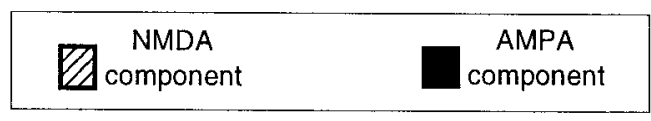

A

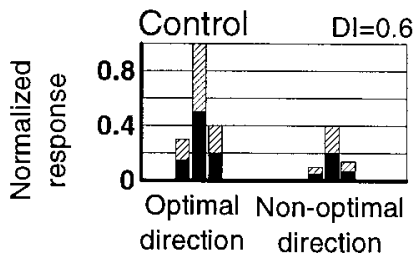

C

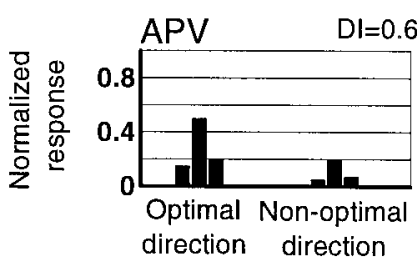

$E$

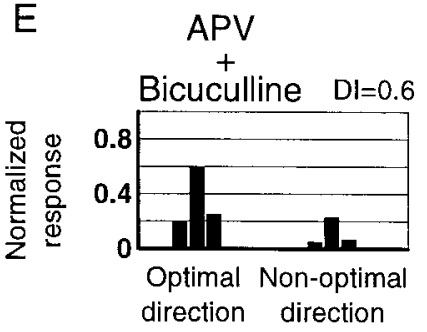

B

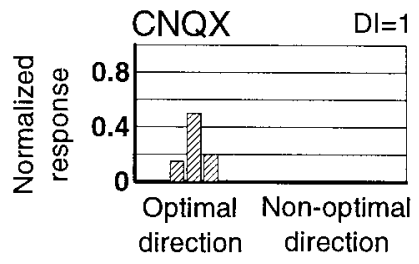

D

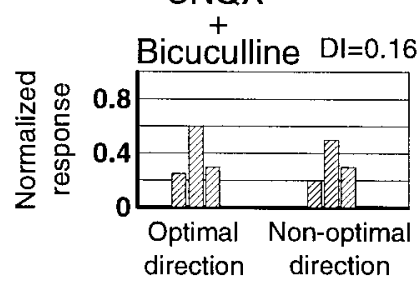

F

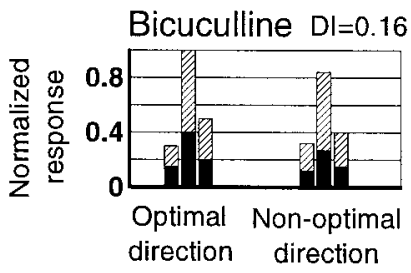

Figure 8. Schematic representation of the effect of NMDA and AMPA receptors on direction selectivity and their regulation by GABA. $A$, In control conditions, direction-selective cells in layer 2/3 have both AMPA and NMDA components that contribute to preferred and nonpreferred responses. Shown here is the hypothetical contribution of the two components to a cell with direction index $=0.6$, which is approximately the 50th percentile of cells in our sample (Fig. $2 A, B$ ). Hypothetical responses are shown normalized to the peak response, and the response scale applies to $B-E$ as well. $B, C N Q X$ ejection removes the AMPA component and leaves the NMDA component, which contributes prominently to responses in the preferred direction. NMDA-mediated responses in the nonpreferred direction are reduced disproportionately by GABAergic inhibition, leading to a high direction index. $C$, Ejection of APV leaves the AMPA component, which contributes similarly to both preferred and nonpreferred directions, causing no change in the direction index. $D$, The NMDA-mediated response, particularly that in the nonpreferred direction, is modulated importantly by GABAergic inhibition. Simultaneous application of CNQX and bicuculline leads to a disproportionate increase in the nonpreferred response and to a decrease in the direction index. $E$, The AMPA-mediated response is increased proportionately in both directions by removal of inhibition. Simultaneous ejection of bicuculline and APV increases both the preferred and nonpreferred response and causes no change in the direction index. $F$, GABAergic inhibition reduces both AMPA- and NMDA-mediated responses and particularly the NMDA responses in the nonpreferred direction. Bicuculline thus increase the nonpreferred response more than the preferred response, leading to a decrease in the direction index. The hypothetical responses in $F$ are normalized differently from those in $A-E$.

preferred responses and remains significantly greater after AMPA receptor blockade.

Two lines of evidence indicate that GABAergic inhibition regulates the reduced contribution of NMDA receptors to nonpreferred responses. First, blocking inhibition by application of bicuculline decreases the direction selectivity of cells (Fig. 8F), 

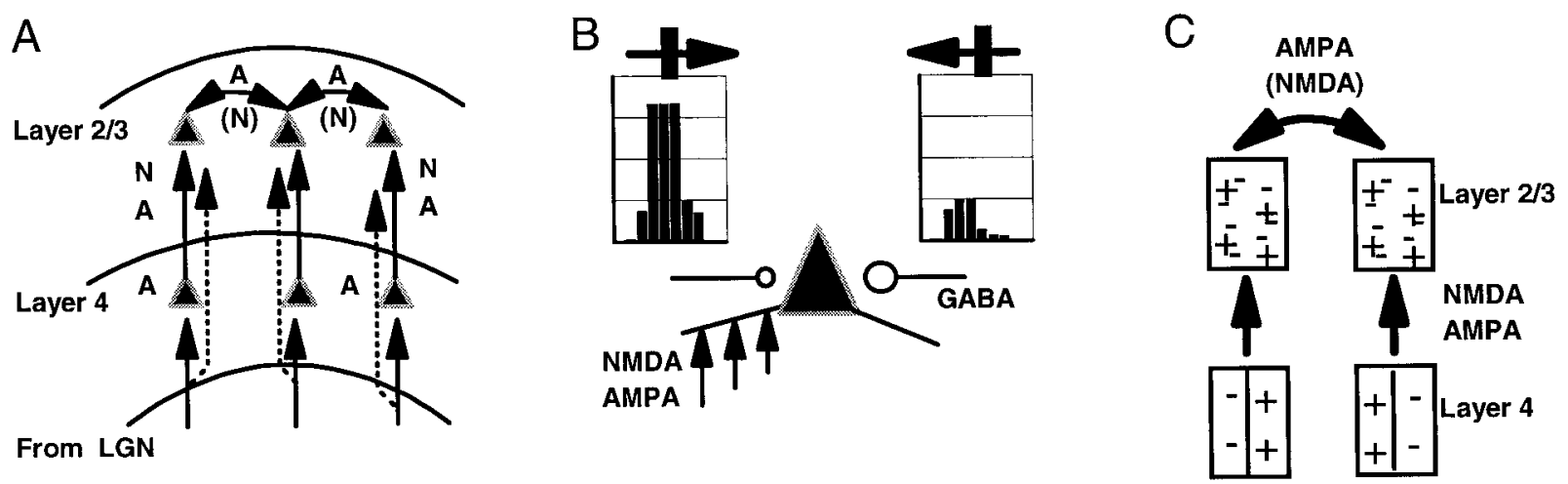

Figure 9. Schematic illustrating the proposed circuits and distribution of receptors at specific connections. $A$, Inputs from the lateral geniculate nucleus $(L G N)$ to cells in layer 4 of V1 are mediated primarily by AMPA receptors (see text for review). These cells provide feedforward inputs to layer $2 / 3$ cells; our data indicate that these connections are mediated by NMDA $(N)$ and AMPA $(A)$ receptors. Inputs from the C layers and the medial interlaminar nucleus of the $L G N$ to layer 3 are shown as dashed lines and are regarded as feedforward connections. Short-range excitatory connections between layer 2/3 cells appear to be mediated primarily by AMPA receptors, with a possible minor contribution from NMDA receptors. $B$, NMDA and AMPA receptors together provide direction-selective feedforward input to layer $2 / 3$ cells. NMDA receptors contribute prominently to responses in the preferred direction (left response histogram), whereas their contribution to responses in the nonpreferred direction (right response histogram) is reduced substantially by GABAergic inhibition (circles). Such inhibition may be greater in the nonpreferred direction. $C$, Simple cells in layer 4 provide feedforward input to cells in layer 2/3 via NMDA and AMPA receptors. Our data suggest that short-range recurrent excitatory connections in layer 2/3 via AMPA receptors are responsible for reducing the spatial phase selectivity of simple cells and creating phase-invariant complex cell responses.

but this effect is reversed by simultaneous application of APV (Fig. 8E), indicating that release of inhibition facilitates NMDA responses in the nonpreferred direction. Second, blockade of inhibition concurrent with AMPA receptor blockade by CNQX reduces direction selectivity (Fig. $8 D$ ). Bicuculline preferentially increases nonpreferred responses, leaving a higher contribution of NMDA responses in the nonpreferred direction.

These data confirm and extend the findings of Fox et al. (1990) that APV causes a proportional reduction in responses of area 17 cells to optimally oriented moving bars as stimulus contrast is increased, whereas application of NMDA increases responses by a proportional amount and quisqualate increases responses by an absolute amount at all contrasts. Importantly, we studied responses in different directions (as also simple and complex cell responses) with APV and CNQX and the modulation of NMDA and AMPA responses by inhibition. NMDA-mediated responses in the nonpreferred direction are reduced nonlinearly by inhibition. Furthermore, the contribution of AMPA receptors to complex cell responses is much more than addition of a constant response component; rather, there is a nonlinear change in the temporal modulation of the response. These argue for specific circuits that engage inhibition for generating direction-selective responses and AMPA receptors for generating complex cell responses (see below and Fig. 9).

The possibility that inhibition regulates NMDA-mediated activity is consistent with other lines of evidence in area 17 (Artola and Singer, 1987; Shirokawa et al., 1989; Schroeder et al., 1997). The relationship between GABAergic inhibition and NMDA function is probably related to the voltage dependence of NMDA receptors; the binding of extracellular $\mathrm{Mg}^{2+}$ to the channel pore is highly dependent on membrane potential, and changes in the latter could significantly modulate NMDA receptor-mediated activity (for review, see Dingledine, 1999). The likely source of inhibition is GABAergic interneurons located within layer 2/3 itself (Crook et al., 1998).

One caveat is that the iontophoresis technique does not allow definitive conclusions about whether all receptors on a cell are affected or whether other cells (either excitatory or inhibitory) in the vicinity could be modifying the responses of the recorded cell. However, the temporal effects of drug application were studied in the first and the second half of the iontophoresis period in several cells and found to be similar. Furthermore, the effect of iontophoresis did not change with ejection time, indicating that most of the affected receptors were in the volume covered by the antagonist since the start of iontophoresis (cf. Hicks, 1984; Hupe et al., 1999).

\section{Phase selectivity of simple and complex cell responses}

In addition to examining the role of AMPA and NMDA receptors in direction selectivity, we examined their role in generating simple and complex responses in the supragranular layers, by analyzing the temporal pattern of response of cells when they were stimulated with drifting gratings (Movshon et al., 1978a,b; Skottun et al., 1991). CNQX caused a dramatic change in complex cell responses, causing them to increase their temporal modulation and respond in a manner similar to that of simple cells. APV did not affect the response modulation of complex cells, and the modulation of simple cell responses was unaffected by CNQX or APV.

Recently, it has been proposed that complex cell responses arise as a consequence of decreasing the phase selectivity of simple cell responses by recurrent intracortical connections (Chance et al., 1999). The model predicts that a decrease in intracortical excitation should cause complex cells to respond like simple cells. If AMPA receptors primarily mediate short-range intracortical excitation (see below), our results agree strongly with this prediction, demonstrating that during blockade of AMPA receptors complex cells behave as simple cells when stimulated with drifting gratings.

Another possibility is that feedforward inputs combined with modulation of inhibition could generate simple and complex cell responses; in the absence of GABAergic inhibition, the spatial segregation of simple cells is lost, and On and Off subregions show greater overlap (Sillito, 1975; Pernberg et al., 1998). In our hands, bicuculline ejection did not change the temporal modula- 
tion of simple (or complex) cell responses. However, some specific differences between our study and the previous studies should be noted. For example, Pernberg et al. (1998) used the reverse correlation method with flashed bar stimuli to study the spatial separation of On and Off subfields of cells in area 18. We studied changes in the temporal modulation of responses in area 17 using drifting gratings. Although the spatial and temporal properties of area 17 cells are related, the subfield expansion during bicuculline iontophoresis may not relate in a simple way to the temporal structure of the grating response. Finally, Pernberg et al. (1998) found the subfield expansion in three of six simple cells, and the results of both Pernberg et al. and the present study derive from a small sample.

We propose that AMPA and NMDA receptors in layer 2/3 have different spatial distributions on cells, with both present on the same cell but in different proportions at different inputs (Fig. $9 A$ ). Both receptors mediate feedforward connections, and these afferents provide the necessary input for direction selectivity in layer 2/3 (Fig. 9B). Our data are consistent with spatiotemporal asymmetry and enhancement of excitation in feedforward pathways as crucial for direction selectivity in layer $2 / 3$, with a prominent role for NMDA receptors in generating the preferred response and a role for GABAergic inhibition in reducing the nonpreferred response. In contrast to feedforward connections, local recurrent connections are mainly mediated by AMPA receptors (with a possible small contribution from NMDA receptors), and they are responsible for smearing the phase selectivity of simple cells to create phase-invariant complex cell responses (Fig. 9C).

The suggestion that short-range excitation between cortical cells is mediated primarily by AMPA receptors is consistent with the fact that fast EPSCs that are evoked in supragranular layer cells in area 17 by adjacent intralaminar stimulation are not APV sensitive (Hirsch and Gilbert, 1991). In somatosensory cortex, intracellular recording of unitary EPSCs in layer 4 and the supragranular cortex indicates that both thalamocortical and intracortical EPSCs are mediated by AMPA receptors and have similar characteristics (Gil et al., 1999). In slices of area 17, white matter stimulation evokes EPSPs in the supragranular layers that have NMDA- and AMPA-mediated components (Shirokawa et al., 1989). Short-latency responses because of feedforward and local recurrent connections are primarily AMPA mediated, whereas long-latency responses because of horizontal connections have significant NMDA components (Langdon and Sur, 1990, 1992). Furthermore, long-range horizontal inputs to layer $2 / 3$ cells in area 17 can sum nonlinearly with feedforward or short-range inputs, indicative of NMDA receptor involvement in the long-range connections (Yoshimura et al., 2000). Thus, it is likely that there is even finer spatial segregation of glutamate receptors associated with specific inputs on layer $2 / 3$ cells. Together with the modulation of responses (particularly those mediated by NMDA receptors) by inhibition, the specific relationship between receptor types and anatomical connections provides a rich substrate for dynamic control of emergent responses in the cortex.

\section{REFERENCES}

Artola A, Singer W (1987) Long-term potentiation and NMDA receptors in rat visual cortex. Nature 330:649-652.

Barlow HB, Levick WR (1965) The mechanism of directionally selective units in rabbit's retina. J Physiol (Lond) 178:477-504.

Bishop PO, Kato H, Orban GA (1980) Direction-selective cells in complex family in cat striate cortex. J Neurophysiol 43:1266-1283.
Chance FS, Nelson SB, Abbott LF (1999) Complex cells as cortically amplified simple cells. Nat Neurosci 2:277-282.

Crook JM, Kisvarday ZF, Eysel UT (1997) GABA-induced inactivation of functionally characterized sites in cat striate cortex: effects on orientation tuning and direction selectivity. Vis Neurosci 14:141-158.

Crook JM, Kisvarday ZF, Eysel UT (1998) Evidence for a contribution of lateral inhibition to orientation tuning and direction selectivity in cat visual cortex: reversible inactivation of functionally characterized sites combined with neuroanatomical tracing techniques. Eur J Neurosci 10:2056-2075.

Dingledine R (1999) The glutamate receptor ion channels. Pharmacol Rev 51:7-61.

Douglas RJ, Koch C, Mahowald M, Martin KA, Suarez HH (1995) Recurrent excitation in neocortical circuits. Science 269:981-985.

Fox K, Sato H, Daw N (1989) The location and function of NMDA receptors in cat and kitten visual cortex. J Neurosci 9:2443-2454.

Fox K, Sato H, Daw N (1990) The effect of varying stimulus intensity on NMDA-receptor activity in cat visual cortex. J Neurophysiol 64:1413-1428.

Ganz L, Felder R (1984) Mechanism of directional selectivity in simple neurons of the cat's visual cortex analyzed with stationary flash sequences. J Neurophysiol 51:294-324.

Gil Z, Connors BW, Amitai Y (1999) Efficacy of thalamocortical and intracortical synaptic connections: quanta, innervation, and reliability. Neuron 23:385-397.

Gilbert CD, Wiesel TN (1979) Morphology and intracortical projections of functionally characterized neurones in the cat visual cortex. Nature 280:120-125

Goodwin AW, Henry GH (1975) Direction selectivity of complex cells in cats: a comparison with simple cells. J Neurophysiol 38:1524-1540.

Gordon B, Tseng YL, Jaeger R, Petrovic A, Tovar K (1995) The development of MK-801, kainate, AMPA, and muscimol binding sites in cat visual cortex. Vis Neurosci 2:241-252.

Gutierrez-Igarza K, Fogarty DJ, Perez-Cerda F, Donate-Oliver F, Albus K, Matute C (1996) Localization of AMPA-selective glutamate receptor subunits in the adult cat visual cortex. Vis Neurosci 13:61-72.

Hicks TP (1984) The history and development of microiontophoresis in experimental neurobiology. Prog Neurobiol 22:185-240.

Hirsch JA, Gilbert CD (1991) Synaptic physiology of horizontal connections in the cat's visual cortex. J Neurosci 11:1800-1809.

Hubel DH, Wiesel TN (1962) Receptive field, binocular interactions and functional architecture in the cat's visual cortex. J Physiol (Lond) 160:106-194.

Hupe JM, Chouvet G, Bullier J (1999) Spatial and temporal parameters of cortical inactivation by GABA. J Neurosci Methods 86:129-143.

Jagadeesh B, Wheat HS, Ferster D (1993) Linearity of summation of synaptic potentials underlying direction selectivity in simple cells of the cat visual cortex. Science 262:1901-1904.

Jagadeesh B, Wheat HS, Kontsevich LL, Tyler CW, Ferster D (1997) Direction selectivity of synaptic potentials in simple cells of the cat visual cortex. J Neurophysiol 78:2772-2789.

Katz LC, Shatz CJ (1996) Synaptic activity and the construction of cortical circuits. Science 74:1133-1138.

Kirkwood A, Bear MF (1994) Homosynaptic long-term depression in the visual cortex. J Neurosci 14:3404-3412.

Kwon YH, Esguerra M, Sur M (1991) NMDA and non-NMDA receptors mediate visual responses of neurons in the cat's lateral geniculate nucleus. J Neurophysiol 66:414-428.

Langdon RB, Sur M (1990) Components of field potentials evoked by white matter stimulation in isolated slices of primary visual cortex: spatial distributions and synaptic order. J Neurophysiol 64:1484-1501.

Langdon RB, Sur M (1992) The effects of selective glutamate receptor antagonists on synchronized firing bursts in layer III of rat visual cortex. Brain Res 599:283-296.

Livingstone MS (1998) Mechanisms of direction selectivity in macaque V1. Neuron 20:509-526.

McLean J, Palmer LA (1989) Contribution of linear spatiotemporal receptive field structure to velocity selectivity of simple cells in area 17 of cat. Vision Res 29:675-679.

Miller KD, Chapman B, Stryker M (1989) Visual responses in adult cat visual cortex depend on $N$-methyl-D-aspartate receptors. Proc Natl Acad Sci USA 86:5183-5187.

Movshon JA, Thompson ID, Tolhurst DJ (1978a) Spatial summation in the receptive fields of simple cells in the cat's striate cortex. J Physiol (Lond) 283:53-77.

Movshon JA, Thompson ID, Tolhurst DJ (1978b) Receptive field organization of complex cells in the cat's striate cortex. J Physiol (Lond) 283:79-99.

Murthy A, Humphrey AL (1999) Inhibitory contributions to spatiotemporal receptive-field structure and direction selectivity in simple cells of cat area 17. J Neurophysiol 81:1212-1224.

Murthy A, Humphrey AL, Saul AB, Feidler JC (1998) Laminar differences in the spatiotemporal structure of simple cell receptive fields in cat area 17. Vis Neurosci 15:239-256.

Nelson S, Toth L, Sheth B, Sur M (1994) Orientation selectivity of 
cortical neurons during intracellular blockade of inhibition. Science 265:774-777.

Pernberg J, Jirmann KU, Eysel UT (1998) Structure and dynamics of receptive fields in the visual cortex of the cat (area 18) and the influence of GABAergic inhibition. Eur J Neurosci 10:3596-3606.

Reid RC, Soodak RE, Shapley RM (1987) Linear mechanisms of directional selectivity in simple cells of cat striate cortex. Proc Natl Acad Sci USA 84:8740-8744.

Reid RC, Soodak RE, Shapley RM (1991) Directional selectivity and spatiotemporal structure of receptive fields of simple cells in cat striate cortex. J Neurophysiol 66:505-529.

Rivadulla C, Sharma J, Sur M (1999) Role of NMDA and AMPA glutamate receptors in orientation and direction selectivity of V1 neurons. Soc Neurosci Abstr 25:677.

Rosier AM, Arckens L, Orban GA, Vandesande F (1993) Laminar distribution of NMDA receptors in cat and monkey visual cortex visualized by [3H]-M K-801 binding. J Comp Neurol 335:369-380.

Sato H, Katsuyama N, Tamura H, Hata Y, Tsumoto T (1995) Mechanisms underlying direction selectivity of neurons in the primary visual cortex of the macaque. J Neurophysiol 74:1382-1394.

Schroeder CE, Javitt DC, Steinschneider M, Mehta AD, Givre SJ, Vaughan Jr HG, Arezzo JC (1997) N-methyl-D-aspartate enhancement of phasic responses in primate neocortex. Exp Brain Res 114:271-278.

Shirokawa T, Nishigori A, Kimura F, Tsumoto T (1989) Actions of excitatory amino acid antagonists on synaptic potentials of layer II/III neurons of the cat's visual cortex. Exp Brain Res 78:489-500.

Sillito AM (1975) The contribution of inhibitory mechanisms to the receptive field properties of neurones in the striate cortex of the cat. J Physiol (Lond) 250:305-329.

Sillito AM (1977) Inhibitory processes underlying the directional specificity of simple, complex and hypercomplex cells in the cat's visual cortex. J Physiol (Lond) 271:699-720.

Sillito AM, Murphy PC, Salt TE, Moody CI (1990) Dependence of retinogeniculate transmission in cat on NMDA receptors. J Neurophysiol 63:347-355.

Skottun BC, De Valois RL, Grosof DH, Movshon JA, Albrecht DG, Bonds AB (1991) Classifying simple and complex cells on the basis of response modulation. Vision Res 31:1079-1086.

Suarez H, Koch C, Douglas R (1995) Modeling direction selectivity of simple cells in striate visual cortex within the framework of the canonical microcircuit. J Neurosci 15:6700-6719.

Taylor WR, He S, Levick WR, Vaney DI (2000) Dendritic computation of direction selectivity by retinal ganglion cells. Science 289:2347-2350.

Tsumoto T, Eckart W, Creutzfeldt OD (1979) Modification of orientation sensitivity of cat visual cortex neurons by removal of GABAmediated inhibition. Exp Brain Res 34:351-363.

Yoshimura Y, Sato H, Imamura K, Watanabe Y (2000) Properties of horizontal and vertical inputs to pyramidal cells in the superficial layers of the cat visual cortex. J Neurosci 20:1931-1940. 